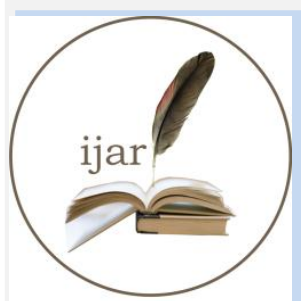

ISSN NO. 2320-5407

\section{Journal Homepage: - www.journalijar.com INTERNATIONAL JOURNAL OF ADVANCED RESEARCH (IJAR)}

Article DOI: $10.21474 /$ IJAR01/10265

DOI URL: http://dx.doi.org/10.21474/IJAR01/10265
INTERNATIONAL JOURNAL OF ADVANCED RESEARCH (JJAR)

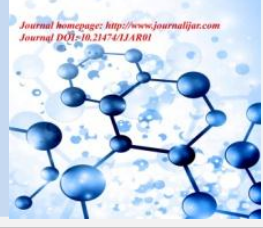

RESEARCH ARTICLE

\title{
RELATIONSHIP BETWEEN MOLAR PREGNANCY AND THYROID FUNCTION IN KINGDOM OF SAUDI ARABIA
}

\author{
Afaf Abdulrahman Yaslam ${ }^{1}$, Hoda Jehad Abousada ${ }^{2}$, Rahaf Salah Ahmad ${ }^{3}$, Sara Osama Abulkhair ${ }^{3}$, Aram \\ Saleh O Bafanaa ${ }^{3}$, Abrar Assad M Bukhari ${ }^{4}$, Alaa Essam Al-Ghamdi ${ }^{5}$ and Sefa Mehmet Emin Altun ${ }^{6}$ \\ 1. Consultanat OB/GYN, Obstetric and Gynecology Department, King Abdullah Medical Complex, Jeddah, Saudi \\ Arabia. \\ 2. Medical intern, Ibn Sina National College, KSA (postal address: Jeddah, Al-Thaghr neighborhood 22338). \\ 3. Medical intern, King Abdulaziz University, KSA. \\ 4. Medical intern, Ibn Sina National College, KSA. \\ 5. Medical intern, Batterjee Medical College, KSA. \\ 6. Medical intern, Umm al-Qura University, KSA.
}

\section{Manuscript Info}

Manuscript History

Received: 13 November 2019

Final Accepted: 25 December 2019

Published: January 2020

\section{Abstract}

\section{Introduction:-}

A molar pregnancy - also known as hydatidiform mole - there are two types of molar pregnancy, complete molar pregnancy and partial molar pregnancy. In a complete molar pregnancy, the placental tissue is abnormal and swollen and appears to form fluid-filled cysts. There's also no formation of fetal tissue. In a partial molar pregnancy, there may be normal placental tissue along with abnormally forming placental tissue. There may also be formation of a fetus, but the fetus is not able to survive, and is usually miscarried early in the pregnancy. (Mayo Clinic, 2019)

\section{Rationale:}

The importance of this research is that it has not been presented before in a way that determines the prevalence of molar pregnancy with relationship in thyroid gland dysfunction, especially in Saudi Arabia ,

Which means that this will be the first and will be unique, while the molar pregnancy has become very prevalent nowadays in these generations.

\section{Literature review:}

According to the other previous study like:

Thyroid function in molar pregnancy:

The result was:1) some patients with molar pregnancy display a marked elevation of serum T4, T3, and free T4 concentrations, probably as a result of the action of a thyroid stimulator which is closely related to serum hCG or may be hCG itself; 2) T4 production rates are increased in these patients, and the pituitary response to TRH in a manner similar to that found in thyrotoxicosis. Despite this, frank clinical thyrotoxicosis is usually absent, possibly because of relatively low serum T3/T4 ratios, possibly because of the limited duration of thyroid hyper function, and possibly because of other factors that for the present remain unknown. (Nagataki S, 1977), I very much agree with this Because it is the first and oldest of all studies and enough that it is the first as it concluded that and documented 
it and worked to publish it although it is very old time and although this study is not inside Saudi Arabia, but this is unique and integrated as a start and start Good for this topic.

On the other hand,I regret to say that there is no research on this subject within Saudi Arabia.

maybe this is a good way for my research to begin good start to be considered a unique and the first in Saudi Arabia

Prevalence of gestational trophoblastic disease. A single institution experience the conclusion was:

The incidence of GTD has declined with the rapid socio-medical development of the KSA, and is now comparable to that of Europe. The optimal management of this disease depends on prompt diagnosis, correct stratification of the risk category and appropriate treatment using various modalities such as chemotherapy and surgery.(TY, 2003) It is strange that I find this only study on the prevalence of molar pregnancy in Saudi Arabia and I regret to say that a long time ago, but I am very happy that it is the first study to raise the subject and agree with this study in an integrated An old.

\section{Research Aim:}

To determine the relationship between molar pregnancy and thyroid function in kingdom of Saudi Arabia.

\section{Objectives:-}

1. To discover the most affected age by molar pregnancy.

2. To determine the relationship between delayed first pregnancy and the incidence of molar pregnancy.

3. Percentage of molar pregnancy to thyroid dysfunction.

\section{Methodology:-}

Study design:

This is an analytical cross-sectional study.

Study Setting and period:

This is an analytical cross-sectional study conducted in kingdom of saudia Arabia (from females IP and OP), from 1/4/2019 till 19/10/2019.

Study population and sampling:

Study participants:

Inclusion criteria:

females married or who were previously married. Exclusion criteria; males and Virgin girls who have never been married.

\section{Sampling Method:-}

The study will be carried out by questionnaire.

\section{Sampling size:}

Sample size was calculated using OpenEpi for sample size calculation for cross sectional studies, hypothesizing the true answers Accordingly, $\mathbf{4 3 1}$ participants were gathered from the hospital patients. score of prevalence of who have suffered from molar pregnancy $11.60 \%$, prevalence of who suffering from health problems in the thyroid function $16.24 \%$.

According to the prevalence study, the results indicated that $14.62 \%$ of the respondents have hypothyroidism problem.

\section{Measurements:-}

Explanatory variables:

1. Sociodemographic characteristics: age.

2. Disease-related information: molar pregnancy, number of molar pregnancy,thyroid function, time of thyroid function problem, type of thyroid function problem. 


\section{Outcome measures:}

The outcome measure is by counting the ratio of the number of patients have suffered from molar pregnancy this will be measured using:

By determining the extent of the disease in addition to the associated with health problems in the thyroid function.

\section{Prevalence study:}

will be carried to test the questionnaire if easily understood and the response of the participants. Data from the crosssectional study will be used to calculate the sample size.

\section{Data Management and Analysis plan:}

Data will be entered and analyzed using SPSS version 17.0 Descriptive statistics will be performed and categorical data will be displayed as frequencies and percentages while measures of central tendencies and measures and dispersion will be used to summarize continuous variables. Univariate and multivariate analysis will be performed to investigate association between exposure factors and associated disease. statistical significance is set at a $\mathrm{P}$ value of 0.05 or less.

\section{Statistical analysis:}

Data were entered and analyzed using Statistical Package for the Social Sciences (SPSS) version 17. Descriptive statistics were displayed as frequencies and percentages for categorical variables. Measures of central tendencies (the median), and measures and dispersion (minimum - maximum) were used to summarize continuous variables, as the continuous variables were not normally distributed when tested by Shapiro-Wilk test. Univariate analysis was performed to investigate the association between the exposure factors with the outcome on the one hand, this was performed using Chi-squared test and Mann-Whitney test. Multivariate analysis to investigate factors independently was performed using binary logistic regression. $\mathrm{P}$ value was set at a significance level of $<0.05$.

\section{Results:-}

In this study, the aim was to determine the relationship between molar pregnancy and thyroid function in kingdom of Saudi Arabia, 431 patients' participants, were consecutively recruited from in patients' clinics, during a period from $1 / 4 / 2019$ to $19 / 10 / 2019$

According to disease $88.40 \%$ did not suffer from molar pregnancy, $16.24 \%$ suffering from health problems in the thyroid function .

Table 1:- Frequency Table, Have you ever suffered from molar pregnancy?

\begin{tabular}{|l|l|l|l|l|l|}
\hline & & Frequency & Percent & Valid Percent & Cumulative Percent \\
\hline \multirow{3}{*}{ Valid } & Yes & 50 & 11.6 & 11.6 & 11.6 \\
\cline { 2 - 6 } & No & 381 & 88.4 & 88.4 & 100.0 \\
\cline { 2 - 6 } & Total & 431 & 100.0 & 100.0 & \\
\hline
\end{tabular}




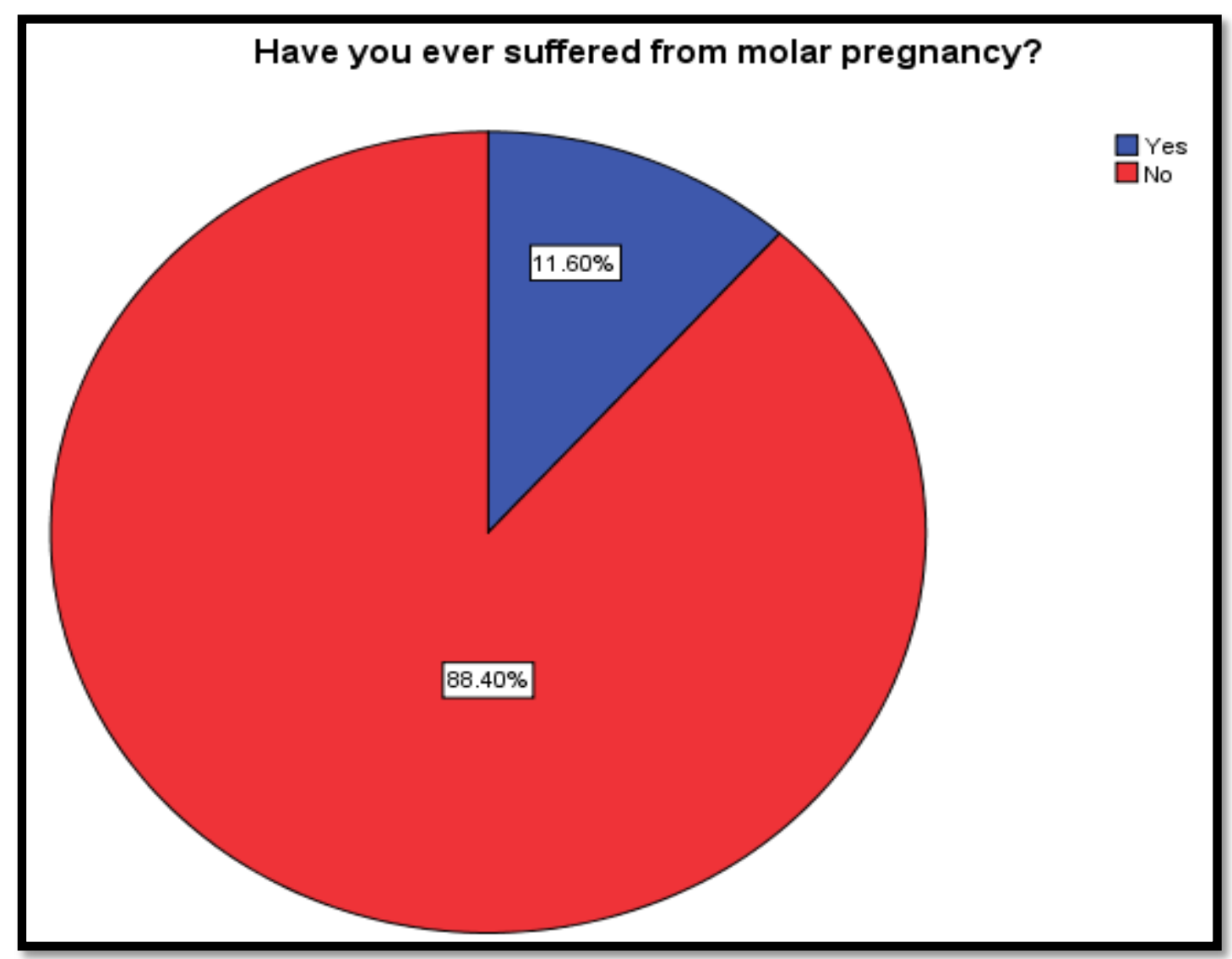

Figure 1:-

Table 2 :- How old were you when you got molar pregnancy?

\begin{tabular}{|l|l|l|l|l|l|}
\hline \multirow{2}{*}{ Valid } & Frequency & Percent & Valid Percent & $\begin{array}{l}\text { Cumulative } \\
\text { Percent }\end{array}$ \\
\cline { 2 - 7 } & below 25 years & 32 & 7.4 & 38.1 & 38.1 \\
\cline { 2 - 6 } & $25-30$ years & 18 & 4.2 & 21.4 & 59.5 \\
\cline { 2 - 6 } & $31-35$ years & 15 & 3.5 & 17.9 & 77.4 \\
\cline { 2 - 6 } & $36-40$ years & 12 & 2.8 & 14.3 & 91.7 \\
\cline { 2 - 6 } & $41-45$ years & 3 & .7 & 3.6 & 95.2 \\
\cline { 2 - 6 } & above 45 years & 4 & .9 & 4.8 & \\
\cline { 2 - 6 } & Total & 84 & 19.5 & 100.0 & \\
\hline Missing & System & 347 & 80.5 & & \\
\hline & Total & 431 & 100.0 & & \\
\hline & & & & & \\
\hline
\end{tabular}




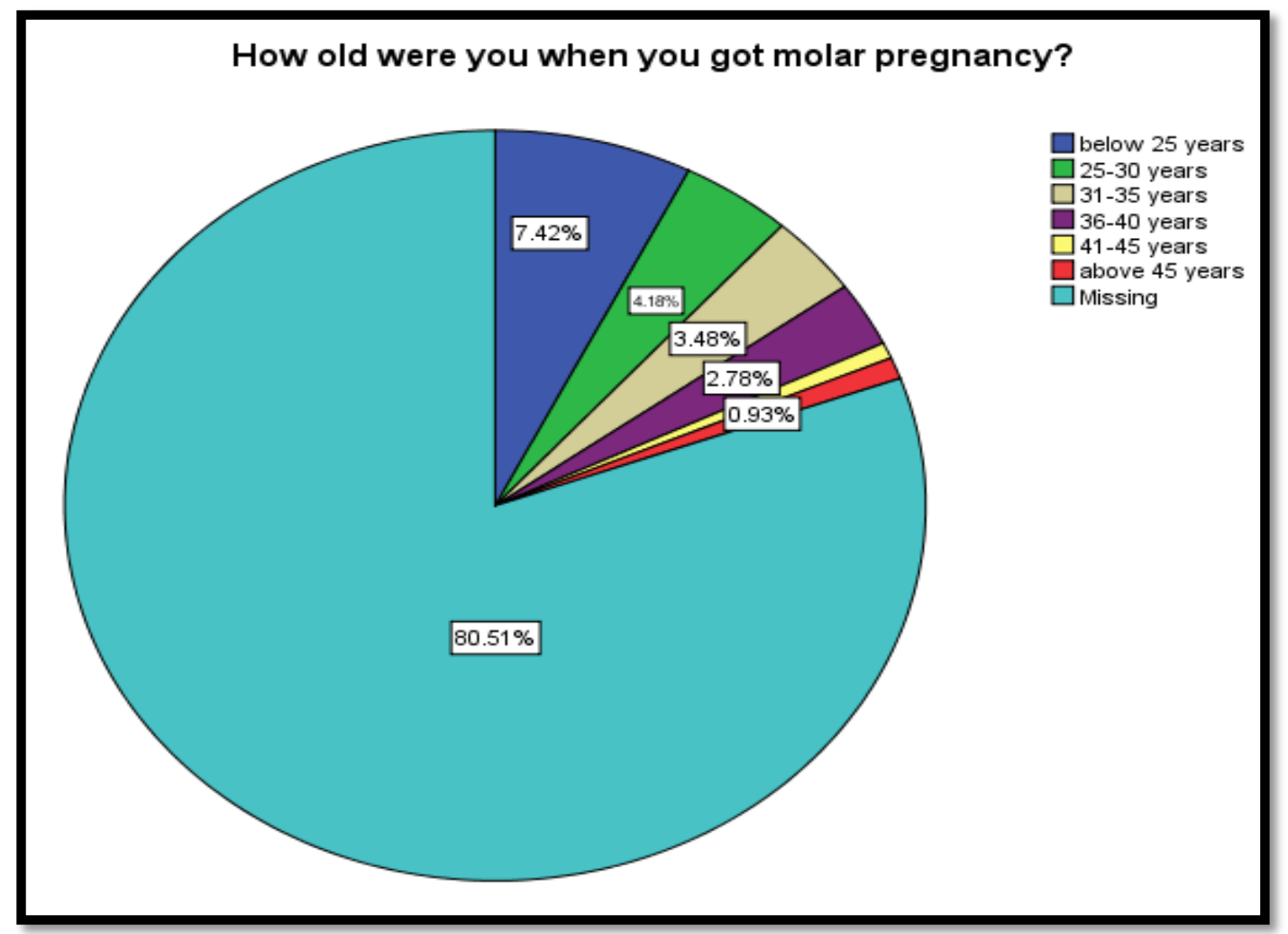

Figure 2:-

Table 3 :- How many number was this pregnancy when you was pregnant with a molar pregnancy?

\begin{tabular}{|c|c|c|c|c|c|}
\hline & & Frequency & Percent & Valid Percent & $\begin{array}{c}\text { Cumulative } \\
\text { Percent }\end{array}$ \\
\hline \multirow{3}{*}{ Valid } & First pregnancy & 17 & 3.9 & 14.2 & 14.2 \\
\cline { 2 - 6 } & Second pregnancy & 13 & 3.0 & 10.8 & 25.0 \\
\cline { 2 - 5 } & Third pregnancy & 8 & 1.9 & 6.7 & 31.7 \\
\cline { 2 - 5 } & Fourth pregnancy & 8 & 1.9 & 6.7 & 38.3 \\
\cline { 2 - 6 } & Fifth pregnancy & 3 & .7 & 2.5 & 40.8 \\
\cline { 2 - 6 } & sixth pregnancy & 1 & .2 & .8 & 41.7 \\
\cline { 2 - 6 } & Other & 70 & 16.2 & 58.3 & \\
\cline { 2 - 6 } & Total & 120 & 27.8 & 100.0 & \\
\hline Missing & System & 311 & 72.2 & & \\
\hline & Total & 431 & 100.0 & & \\
\hline
\end{tabular}




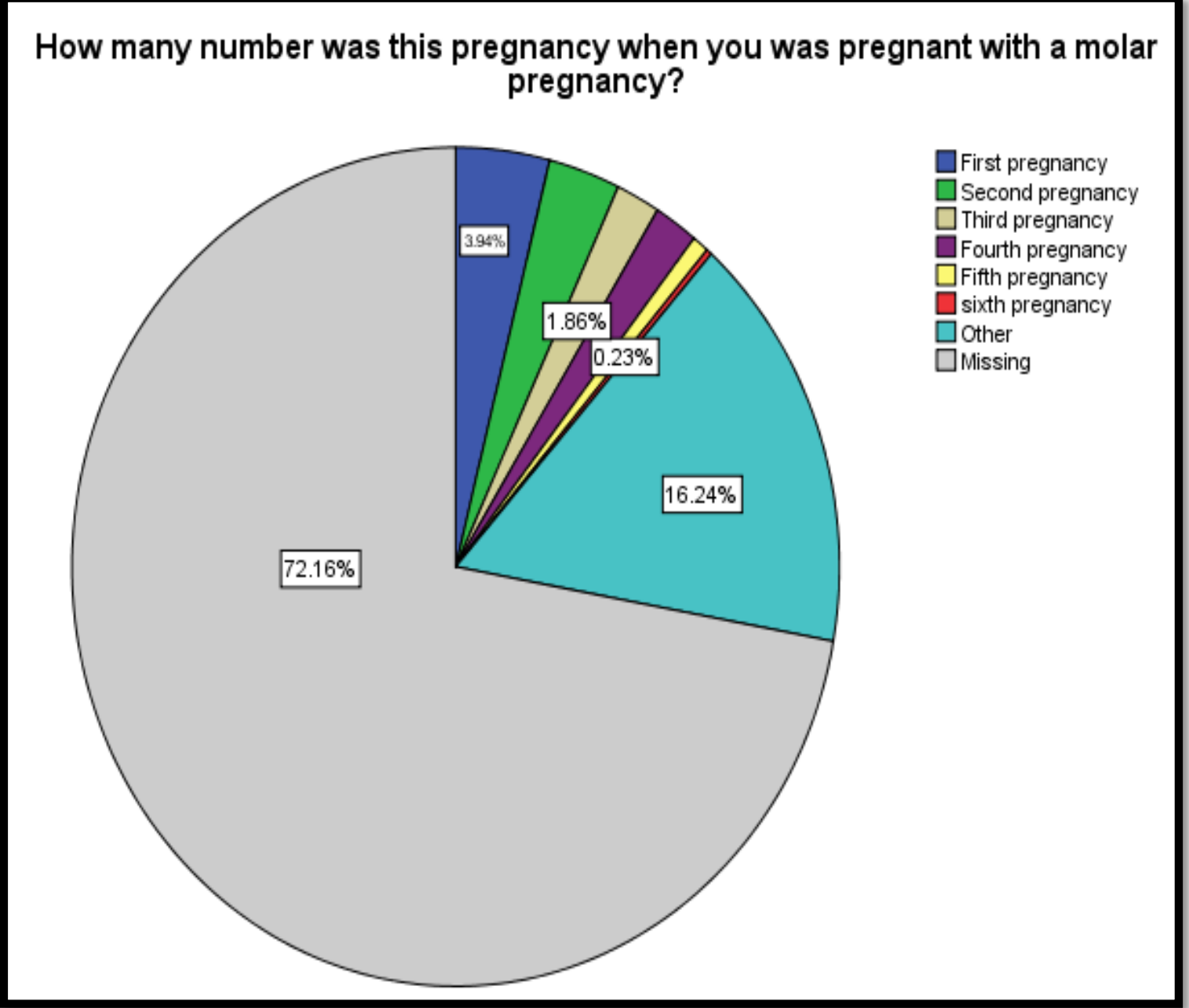

Figure 3:-

Table 4:-Do you suffer from any health problems in the thyroid function?

\begin{tabular}{|l|l|l|l|l|l|}
\hline & & Frequency & Percent & Valid Percent & Cumulative Percent \\
\hline Valid & Yes & 70 & 16.2 & 16.2 & 16.2 \\
\cline { 2 - 6 } & No & 361 & 83.8 & 83.8 & 100.0 \\
\cline { 2 - 6 } & Total & 431 & 100.0 & 100.0 & \\
\hline
\end{tabular}




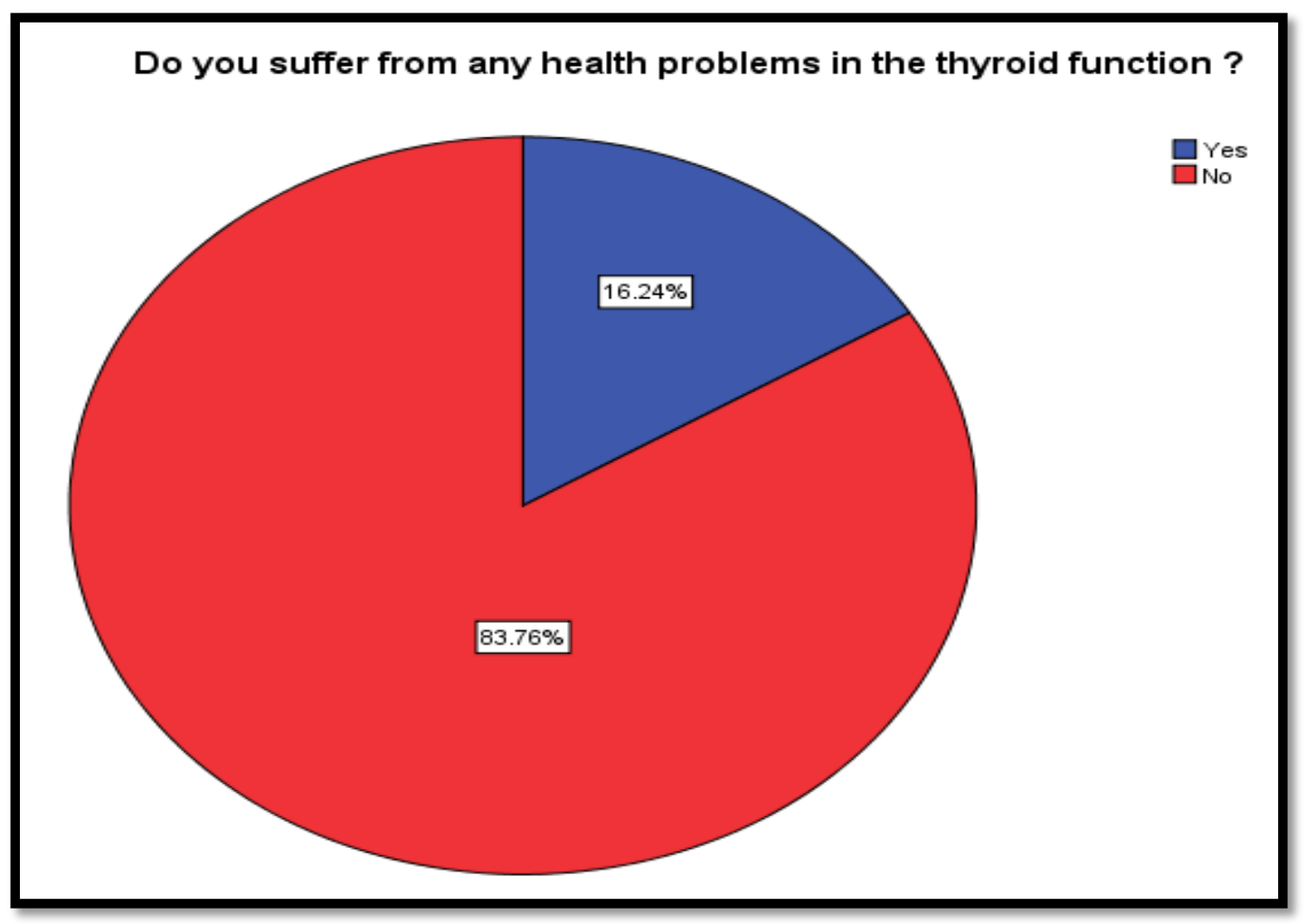

Table 5:- When was the time of thyroid function problems?

\begin{tabular}{|l|l|l|l|l|l|}
\hline \multirow{5}{*}{ Valid } & Frequency & Percent & Valid Percent & $\begin{array}{l}\text { Cumulative } \\
\text { Percent }\end{array}$ \\
\cline { 2 - 6 } & Before the molar pregnancy & 11 & 2.6 & 9.0 & 9.0 \\
\cline { 2 - 6 } & $\begin{array}{l}\text { With molar pregnancy at the } \\
\text { same time }\end{array}$ & 8 & 1.9 & 6.6 & 15.6 \\
\cline { 2 - 6 } & After the molar pregnancy & 3 & .7 & 2.5 & 18.0 \\
\cline { 2 - 6 } & I do not remember & 100 & 23.2 & 82.0 & 100.0 \\
\cline { 2 - 6 } & Total & 122 & 28.3 & 100.0 & \\
\hline Missing & System & 309 & 71.7 & & \\
\hline & Total & 431 & 100.0 & & \\
\hline
\end{tabular}




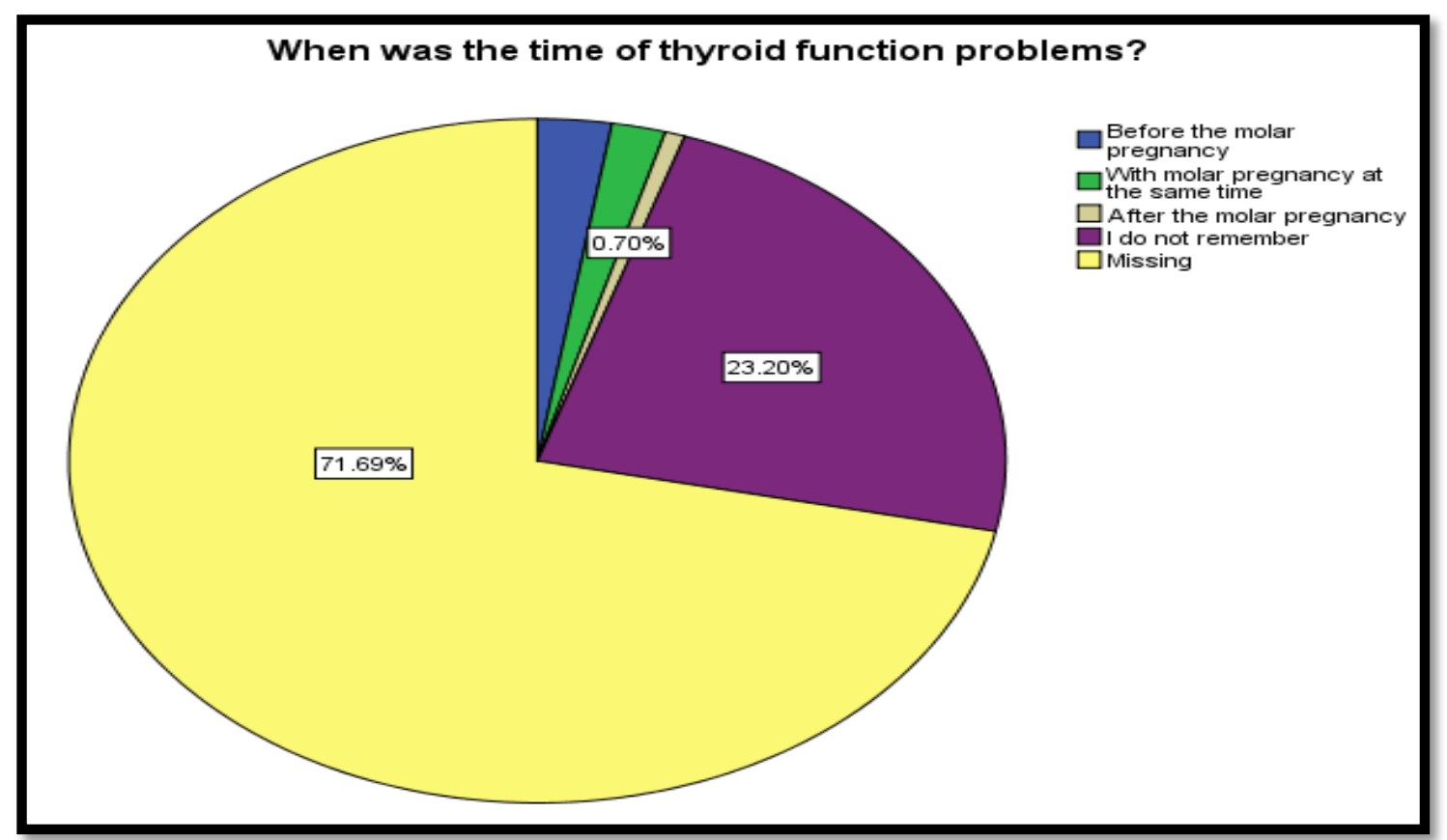

Figure 5:-

Table 6:- Determine your problem in thyroid function?

\begin{tabular}{|l|l|l|l|l|l|}
\hline & & Frequency & Percent & Valid Percent & $\begin{array}{l}\text { Cumulative } \\
\text { Percent }\end{array}$ \\
\hline Valid & Hypothyroidism & 63 & 14.6 & 14.6 & 14.6 \\
\cline { 2 - 6 } & Hyperthyroidism & 12 & 2.8 & 2.8 & 17.4 \\
\cline { 2 - 6 } & I have nothing & 356 & 82.6 & 82.6 & 100.0 \\
\cline { 2 - 6 } & Total & 431 & 100.0 & 100.0 & \\
\hline
\end{tabular}

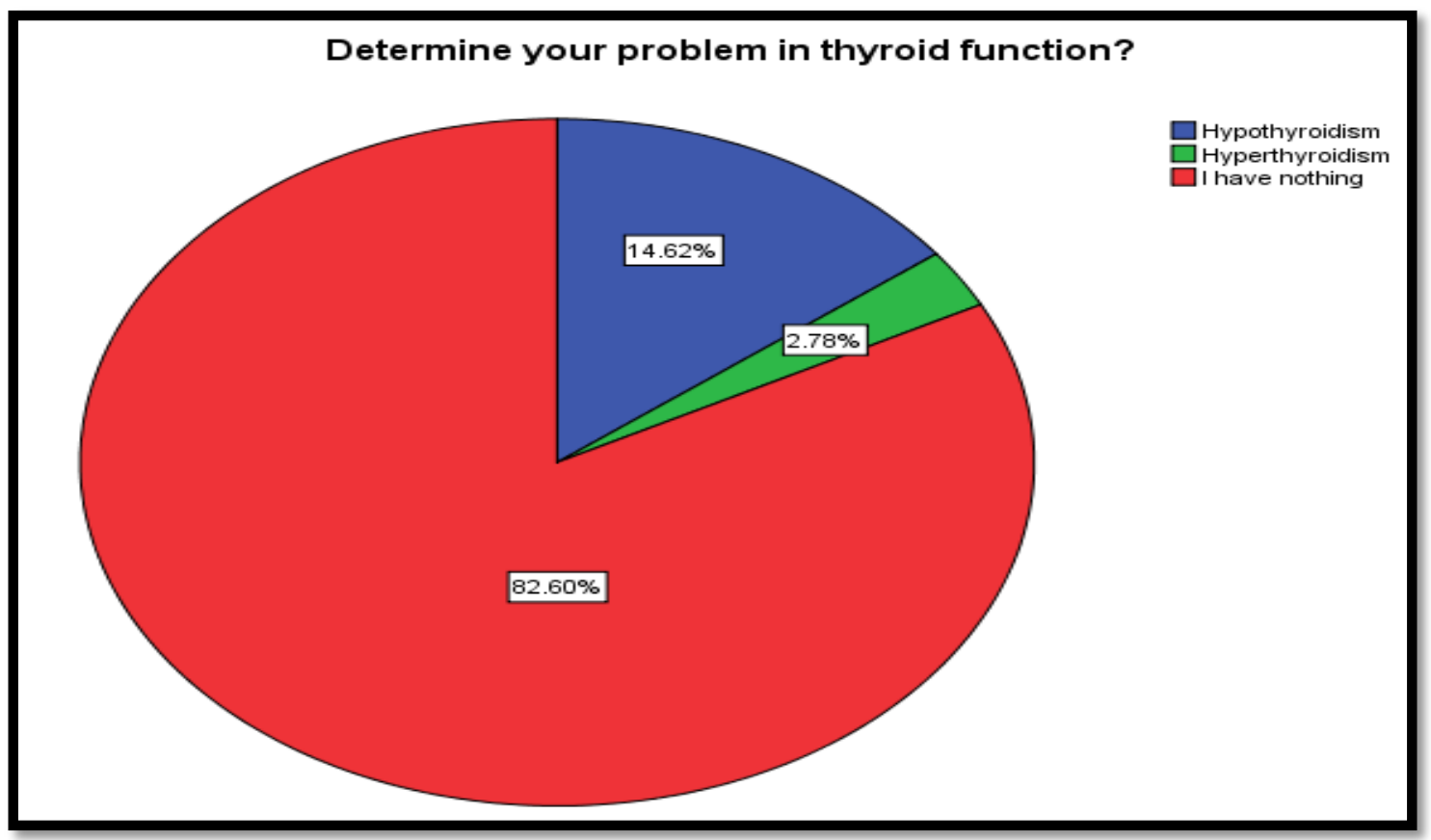

Figure 6 


\section{Discussion:-}

This study was based on a number of $\mathbf{4 3 1}$ participants, from this study as the number of females have suffered from molar pregnancy is 50, 63 of them have kidney disease, of them having health problems in the thyroid function.

The current study showed statistically significant ( $\mathrm{P}$ value is 0.01$)$ and ( $\mathrm{P}$ value is 0.05 ), Through the questionnaire it was found that there is a strong correlation between cluster pregnancy and thyroid function..

\section{Conclusion:-}

1. The results of the study showed positive results in terms of decreased incidence of molar pregnancy.

2. The results demonstrate that there is a strong correlation between cluster pregnancy and thyroid function.

3. The results showed that most of the respondents do not suffer from any health problems in the thyroid function which is a good thing.

4. The results demonstrated that there is a strong correlation between the type of problem in the thyroid gland and the cluster pregnancy.

5. Also, there is a strong correlation between the type of problem in the thyroid gland and the number of the pregnancy when the woman is pregnant with a molar pregnancy.

\section{Recommendation:-}

we recommend setting up health education programs about the molar pregnancy and thyroid diseases, this health problem must be presented broadly and beneficially and, in a way, that everyone understands, as most deal with the thyroid disease by ignoring and not being important, work should be done on health conferences and medical discussions on that.

\section{Acknowledgement:-}

The authors would like to thank the participants for their great cooperation, Participants will be especially from in patients' hospitals selected and carried out by questionnaire.

\section{We thank the data collector:}

Abdulmajeed Salman Aljasim, who collected the data from the patients, he worked hard to collect data greatly, and a large sample number was collected for his great effort.

\section{Ethical considerations :}

Administrative approval will be sought from the unit of biomedical ethics research committee Ethical approval will be sought from the ethical committee of the faculty of medicine, king fahad armed hospital. An informed consent will be sought from the participants.

\section{Source of funding, self-funded:}

This research did not receive any specific grant from funding agencies in the public, commercial, or not-for-profit sectors.

\section{References:-}

1. Mayo Clinic. (2019). Molar pregnancy - Symptoms and causes. [online] Available at: https://www.mayoclinic.org/diseases-conditions/molar-pregnancy/symptoms-causes/syc-20375175 [Accessed 25 Aug. 2019].

2. Rajatanavin R, Chailurkit LO, Srisupandit S, et al. Trophoblastic hyperthyroidism: clinical and biochemical features of five cases. Am J Med 1988;85:237-41 [PubMed] [Google Scholar]

3. Goodwin T, Hershman J. Hyperthyroidism due to inappropriate production of human chorionic gonadotropin. Clin Obstet Gynecol 1997;40:32-44 [PubMed] [Google Scholar]

4. Soutter W, Norman R, Green-Thompson R. The management of choriocarcinoma causing severe thyrotoxicosis. Two case reports. Br J Obstet Gynaecol 1981;88:938-43 [PubMed] [Google Scholar]

5. Nagataki S, e. (1977). Thyroid function in molar pregnancy. - PubMed - NCBI. [online] Ncbi.nlm.nih.gov. Available at: https://www.ncbi.nlm.nih.gov/pubmed/402378 [Accessed Feb. 1977].

6. TY, K. (2003). Prevalence of gestational trophoblastic disease. A single institution experience. - PubMed NCBI. [online] Ncbi.nlm.nih.gov. Available at: https://www.ncbi.nlm.nih.gov/pubmed/?term=molar+pregnancy+in+KSA [Accessed 24 Dec. 2003]. 
Appendixes:

Questionnaire

1. Have you ever suffered from molar pregnancy?

- YES

- NO

2. How old were you when you got molar pregnancy?

- below 25 years

- 25-30 years

- 31-35 years

- 36-40 years

- 41-45 years

- $\quad$ above 45 years

3. How many number was this pregnancy when you was pregnant with a molar pregnancy?

- First pregnancy

- Second pregnancy

- Third pregnancy

- $\quad$ Fourth pregnancy

- $\quad$ Fifth pregnancy

- $\quad$ sixth pregnancy

- Other

4. Do you suffer from any health problems in the thyroid function?

- YES

- NO

5. When was the time of thyroid function problems?

- Before the molar pregnancy

- With molar pregnancy at the same time

- After the molar pregnancy

- I do not remember

$-$

6. Determine your problem in thyroid function?

- Hypothyroidism

- Hyperthyroidism

I have nothing 